\title{
Characteristics of Nucleic Acids
}

Knowledge of the structural features of nucleic acids is important to an understanding of their biological function. This section provides information about the major nucleoside/nucleotide constituents and structures for A-, B-, and Z-DNA Some experimentally useful properties of the nucleoside/nucleotide building blocks are listed in Table A.1B.1. The chemical structures of the nucleosides can be seen in Figure A.1B.1, and aspects of nucleotide stereochemistry that are important to an understanding of base pairing and secondary structure can be found in Figures A.1B.2 and A.1B.3 and in Tables A.1B.2 and A.1B.3. Although Watson-Crick pairings play a critical role in defining nucleic acid secondary structures, a wide variety of alternative base pairings can be important in higher-order conformations; some of these are shown in Figure A.1B.4. Figure A.1B.5 depicts the three best characterized helix structures for DNA: A-, B-, and Z-DNA. A comprehensive collection of reviews on all aspects of nucleic acid structure has recently been published (Neidle, 1999).

Table A.1B.1 Physical Characteristics of the Nucleotides ${ }^{a}$

\begin{tabular}{|c|c|c|c|c|c|c|c|c|}
\hline \multirow{2}{*}{ Nucleotide } & \multirow{2}{*}{$\begin{array}{l}\text { Mol. wt. } \\
\text { (g/mol) }\end{array}$} & \multirow{2}{*}{$\begin{array}{l}\lambda_{\max } \\
(\mathrm{nm})\end{array}$} & \multirow{2}{*}{$\begin{array}{l}\lambda_{\min } \\
(\mathrm{nm})\end{array}$} & \multirow{2}{*}{$\begin{array}{c}\varepsilon_{\max } \\
\left(\mathrm{mM}^{-1} \mathrm{~cm}^{-1}\right)\end{array}$} & \multirow{2}{*}{$A_{280} / A_{260}$} & \multicolumn{3}{|c|}{ TLC mobility $^{b}$} \\
\hline & & & & & & $\mathrm{A}$ & B & $\mathrm{C}$ \\
\hline ATP & 507.2 & 259 & 227 & 15.4 & 0.15 & 0 & 6 & 34 \\
\hline ADP & 427.2 & 259 & 227 & 15.4 & 0.16 & 0 & 26 & 54 \\
\hline AMP & 347.2 & 259 & 227 & 15.4 & 0.16 & 11 & 52 & 65 \\
\hline Adenosine $^{c}$ & 267.2 & 260 & 227 & 14.9 & 0.14 & - & - & - \\
\hline $\mathrm{dATP}^{d}$ & 491.2 & 259 & 226 & 15.4 & 0.15 & 0 & - & 35 \\
\hline $\mathrm{dAMP}^{d}$ & 331.2 & 259 & 226 & 15.2 & 0.15 & 11 & 52 & - \\
\hline $\mathrm{dA}$ & 251.2 & 260 & 225 & 15.2 & 0.15 & - & - & - \\
\hline СТP & 483.2 & 271 & 249 & 9.0 & 0.97 & 0 & 11 & 41 \\
\hline CDP & 403.2 & 271 & 249 & 9.1 & 0.98 & 0 & 33 & 64 \\
\hline CMP & 323.2 & 271 & 249 & 9.1 & 0.98 & 15 & 64 & 75 \\
\hline Cytidine & 243.2 & 271 & 250 & 9.1 & 0.93 & - & - & - \\
\hline $\mathrm{dCTP}^{d}$ & 467.2 & 272 & - & 9.1 & 0.98 & 0 & - & 43 \\
\hline dCMP & 307.2 & 271 & 249 & 9.3 & 0.99 & 18 & 65 & - \\
\hline $\mathrm{dC}$ & 227.2 & 271 & 250 & 9.0 & 0.97 & - & - & - \\
\hline GTP & 523.2 & 253 & 223 & 13.7 & 0.66 & 0 & 5 & 25 \\
\hline GDP & 443.2 & 253 & 224 & 13.7 & 0.66 & 0 & 17 & 45 \\
\hline GMP & 363.2 & 252 & 224 & 13.7 & 0.66 & 6 & 40 & 51 \\
\hline Guanosine $^{c}$ & 283.2 & 253 & 223 & 13.6 & 0.67 & - & - & - \\
\hline $\mathrm{dGTP}^{d}$ & 507.2 & 252 & 222 & 13.7 & 0.66 & 0 & - & 26 \\
\hline $\mathrm{dGMP}^{d}$ & 347.2 & 253 & 222 & 13.7 & 0.67 & 6 & 41 & - \\
\hline $\mathrm{dG}$ & 267.2 & 254 & 223 & 13.0 & 0.68 & - & - & - \\
\hline UTP & 484.2 & 262 & 230 & 10.0 & 0.38 & 0 & 14 & 49 \\
\hline UDP & 404.2 & 262 & 230 & 10.0 & 0.39 & 0 & 41 & 71 \\
\hline UMP & 324.2 & 262 & 230 & 10.0 & 0.39 & 20 & 75 & 80 \\
\hline Uridine & 244.2 & 262 & 230 & 10.1 & 0.35 & - & - & - \\
\hline $\mathrm{TTP}^{d}$ & 482.2 & 267 & - & 9.6 & 0.73 & 0 & - & 52 \\
\hline $\mathrm{TMP}^{d}$ & 322.2 & 267 & 234 & 9.6 & 0.73 & 24 & 74 & - \\
\hline Thymidine $^{d}$ & 242.2 & 267 & 235 & 9.7 & 0.70 & - & - & - \\
\hline
\end{tabular}

Current Protocols in Nucleic Acid Chemistry (2000) A.1B.1-A.1B.14

Copyright $\odot 2000$ by John Wiley \& Sons, Inc.

Standard

Nomenclature, Data, and Abbreviations 
Table A.1B.2 Average Torsion Angles for A-, B-, and Z-DNA Backbone (Dickerson, 1992) ${ }^{a}$

\begin{tabular}{|c|c|c|c|}
\hline Torsion Angle & A-DNA & B-DNA & Z-DNA \\
\hline$\alpha\left(\mathrm{O}^{\prime}-\mathrm{P}-\mathrm{O}^{\prime}-\mathrm{C}^{\prime}\right)$ & 287 & 295 & 48,223 \\
\hline$\beta\left(\mathrm{P}-\mathrm{O} 5^{\prime}-\mathrm{C}^{\prime}-\mathrm{C} 4^{\prime}\right)$ & 173 & 167 & 179,221 \\
\hline$\gamma\left(\mathrm{O}^{\prime}-\mathrm{C}^{\prime}-\mathrm{C} 4^{\prime}-\mathrm{C} 3^{\prime}\right)$ & 64 & 51 & 190,55 \\
\hline$\delta\left(\mathrm{C}^{\prime}-\mathrm{C} 4^{\prime}-\mathrm{C} 3^{\prime}-\mathrm{O} 3^{\prime}\right)$ & 78 & 129 & 100,138 \\
\hline$\varepsilon\left(\mathrm{C}^{\prime}-\mathrm{C} 3^{\prime}-\mathrm{O} 3^{\prime}-\mathrm{P}\right)$ & 209 & 203 & 256,299 \\
\hline$\zeta\left(\mathrm{C}^{\prime}-\mathrm{O}^{\prime}-\mathrm{P}-\mathrm{O} 5^{\prime}\right)$ & 283 & 240 & 291,80 \\
\hline$\chi\left({ }^{\prime} 4^{\prime}-\mathrm{Cl}^{\prime}-\mathrm{N}-\mathrm{C} 2(4)\right)$ & 195 & 257 & 67,201 \\
\hline
\end{tabular}

${ }^{a}$ Rotations are given in degrees $\left({ }^{\circ}\right)$. The parameters are illustrated in Figure A.1B.2.

Table A.1B.3 Mean Value of Helix Parameters for A-, B-, and Z-DNA ${ }^{a}$

\begin{tabular}{lcccc}
\hline Parameter & A-DNA & B-DNA & B-DNA mean (range) & Z-DNA \\
\hline X-displacement & -4.1 & 0.8 & $0.5(-0.6$ to 1.5$)$ & $3.0(\mathrm{C}), 3.0(\mathrm{G})$ \\
Y-displacement & - & 0.1 & - & $-2.3(\mathrm{C}), 2.3(\mathrm{G})$ \\
Inclination & 12.0 & 2.4 & $-1.2(-10.9$ to 11.0$)$ & $-6.2(\mathrm{C}),-6.2(\mathrm{G})$ \\
Tip & 11.0 & 0 & $0.1(-11.3$ to 11.3$)$ & $2.9(\mathrm{C}),-2.9(\mathrm{G})$ \\
Buckle & -2.4 & -0.2 & $0.9(-10.6$ to 16.0$)$ & $-6.2(\mathrm{C}), 6.2(\mathrm{G})$ \\
Propeller & -8.3 & -11.1 & $-11.0(-24$ to 5.2$)$ & $-1.3(\mathrm{C}),-1.3(\mathrm{G})$ \\
Opening & - & - & $1.5(-8.4$ to 8.1$)$ & - \\
Shift & - & - & $0(-1.1$ to 1.1$)$ & - \\
Slide & -1.6 & 0.4 & $-0.1(-1.1$ to 1.1$)$ & $5.4(\mathrm{C}-\mathrm{G}),-1.1(\mathrm{G}-\mathrm{C})$ \\
Rise & 2.9 & 3.4 & $3.4(3.2$ to 4.0$)$ & $3.9(\mathrm{C}-\mathrm{G}), 3.5(\mathrm{G}-\mathrm{C})$ \\
Tilt & - & 0 & $-0.2(-7.6$ to 7.6$)$ & 0,0 \\
Roll & 6.3 & 0.6 & $1.8(-12.4$ to 16.0$)$ & $-5.8(\mathrm{C}-\mathrm{G}), 5.8(\mathrm{G}-\mathrm{C})$ \\
Twist & 31.1 & 36.1 & $36.2(21.8$ to 50.6$)$ & $-9.4(\mathrm{C}-\mathrm{G}),-50.6(\mathrm{G}-\mathrm{C})$ \\
\hline
\end{tabular}

${ }^{a}$ Translations are given in angstroms $(\AA)$ and rotations in degrees $\left({ }^{\circ}\right)$. The parameters are illustrated in Figure A.1B.3. The values of the parameters for A-DNA, B-DNA, and Z-DNA are from Dickerson, 1992, Heinemann et al., 1994, and Hartman and Lavery, 1996. 


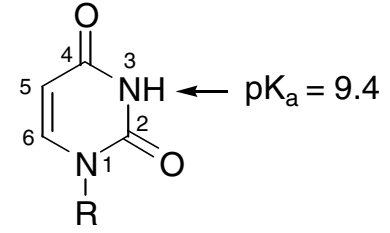

uridine, $\mathrm{R}=$ ribosyl<smiles>Cc1cn(P)c(=O)[nH]c1=[W][Ba]</smiles>

thymidine, $\mathrm{R}=$ deoxyribosyl

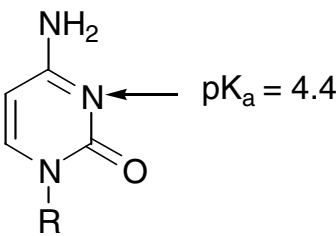

cytidine, $\mathrm{R}=$ ribosyl deoxycytidine, $\mathrm{R}=$ deoxyribosyl<smiles>Cn1cnc2c(N)[n+](C=[As][Ba])cnc21</smiles>

adenosine, $\mathrm{R}=$ ribosyl deoxyadenosine, $\mathrm{R}=$ deoxyribosyl

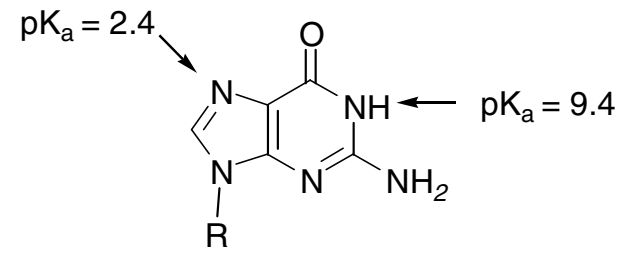

guanosine, $\mathrm{R}=$ ribosyl deoxyguanosine, $R$ = deoxyribosyl
$\mathrm{HO}-$

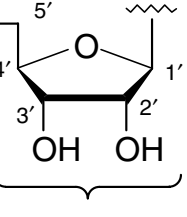

$\mathrm{pK}_{\mathrm{a}}=12.3-12.5$

$\mathrm{R}=$

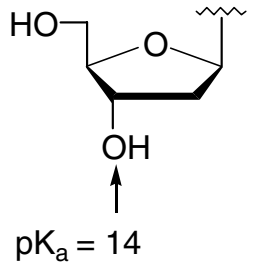

ribosyl

deoxyribosyl

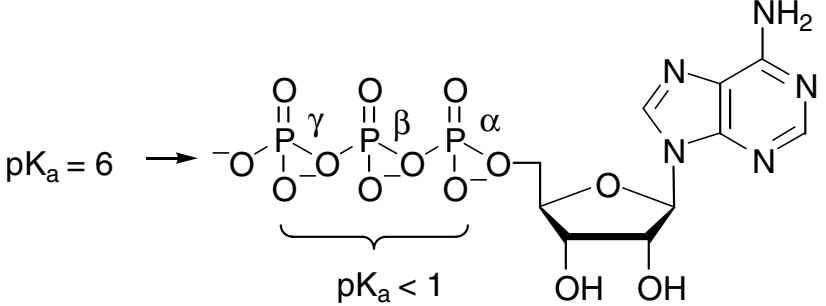

adenosine triphosphate (ATP)
Figure A.1B.1 Line drawings of the nucleosides. The chemical structure that predominates at neutral $\mathrm{pH}$ is shown. Drawings of the nucleotide bases and their associated sugars, either ribose or deoxyribose, are shown separately. In the representations of ribose (by itself and as a nucleoside triphosphate, ATP) and deoxyribose, the bold lines indicate that this portion of the sugar is coming out of the page toward the reader. In this view, the base is found above the plane of the sugar, while the $3^{\prime}$-hydroxyl group is found below the plane of the sugar.

The $\mathrm{pK}_{\mathrm{a}}$ values for all groups are shown; $\mathrm{pK}_{\mathrm{a}}$ values above 7 imply proton association to the pictured structure, while $\mathrm{pK}_{\mathrm{a}}$ values below 7 imply proton dissociation from the pictured structure. The tautomeric form of a given base may change at different $\mathrm{pH}$ values. The $\mathrm{pK}_{\mathrm{a}}$ values given are for nucleotide monophosphates and were taken from Dawson et al. (1987); a fuller discussion of the chemical basis for these values can be found in a review by T'so (1974).

The small numbers adjacent to adenosine, uridine, and ribose indicate the nomenclature of the purines, pyrimidines, and sugars, respectively. Groups appended to a ring have the same numbering as the position to which they are linked; thus, the "O6" moiety of guanosine is the carbonyl oxygen bonded to $\mathrm{C} 6$ in the ring. Similarly, "O3"' on ribose or deoxyribose indicates the oxygen of the hydroxyl group bonded to ${ }^{\prime} 3^{\prime}$ in the ring. The $\alpha, \beta$, and $\gamma$ phosphates in a nucleoside triphosphate (adenosine triphosphate, ATP) are also indicated. 


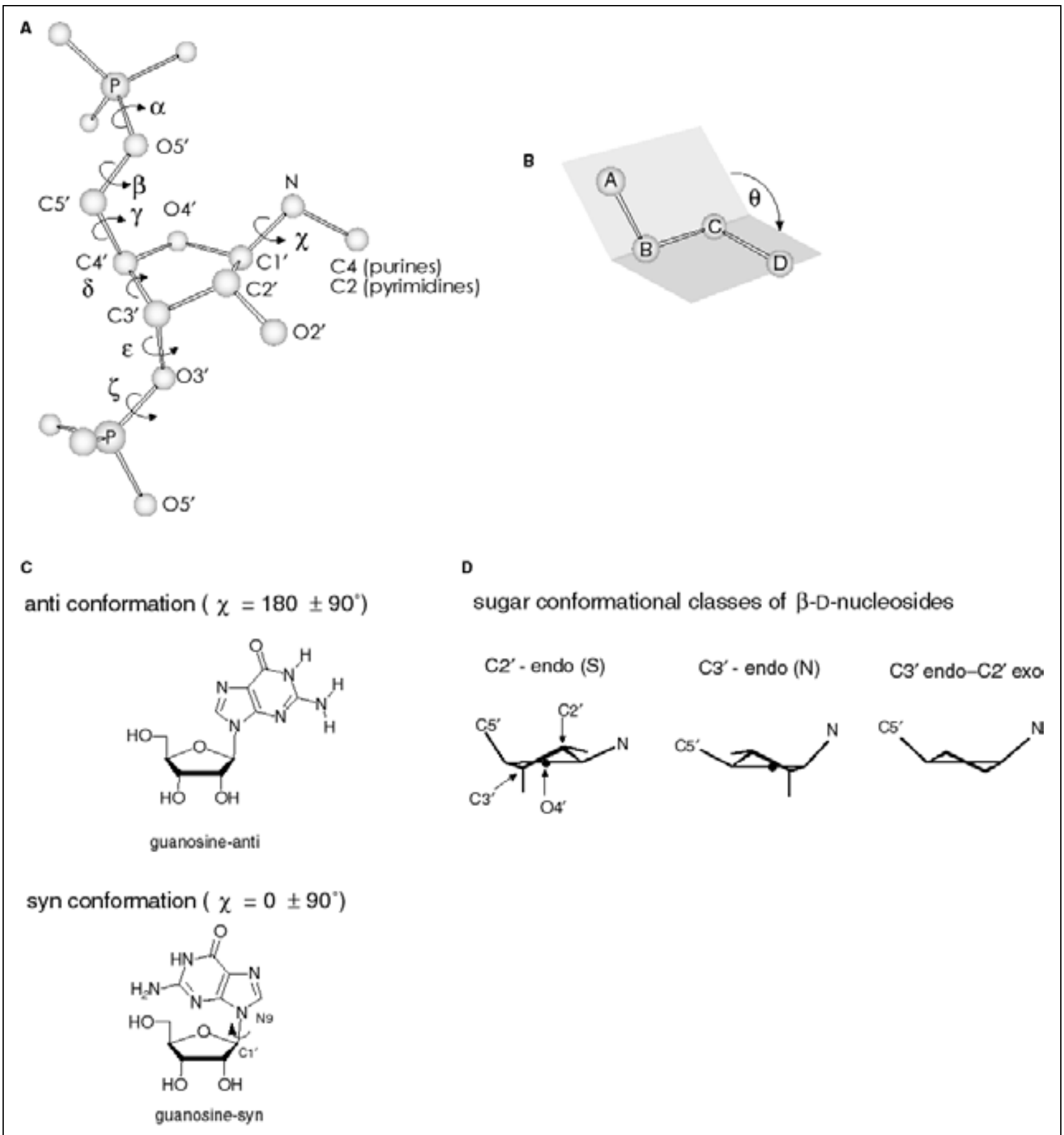

Figure A.1B.2 Nucleotide stereochemistry. (A) Various torsion angles for DNA backbone. Average values for A-, B-, and Z-DNA are given in Table A.1B.2. (B) The torsion angle $(\theta)$ is defined as the angle between the two planes defined by the three bonds A-B-C and B-C-D. When bonds A-B and $\mathrm{C}-\mathrm{D}$ are eclipsed, the torsion angle is 0 . The direction of rotation shown in the figure corresponds to a positive value of $\theta$. (C) Depending on the rotation about the bond between $\mathrm{C}^{\prime}{ }^{\prime}$ of the sugar and either N1 (for pyrimidines) or N9 (for purines), a nucleotide can be described as either "anti" or "syn." Because of steric constraints, nucleotides are generally found in the "anti" configuration, with their Watson-Crick hydrogen bond donor-acceptors swung outward away from the plane of the sugar ring. However, guanosine is sometimes found in a "syn" configuration, both in polynucleotides and in solution. In this form, the bulk of the purine ring is positioned directly over the plane of the sugar. (D) The sugar ring can also adopt different stereochemistries. These are labeled according to which group is bent out of the plane of the ring, and in which direction. If a portion of the ring is bent "upward" toward the base, this is known as "endo," while if it is bent "downward" away from the base, this is known as "exo." The majority of nucleotides cluster in two domains centered at C2'-endo and C3'-endo (Saenger, 1984). In the figure, plain lines represent bonds that are within the plane of the sugar, while bold lines indicate that the bond is bent out of the plane. Hence, "C3' endo-C2' exo" describes a furanose ring in which the $2^{\prime}$ and $3^{\prime}$ carbons have been twisted in opposite directions and the bond connecting them crosses the plane of the ring.

\section{A.1B.4}



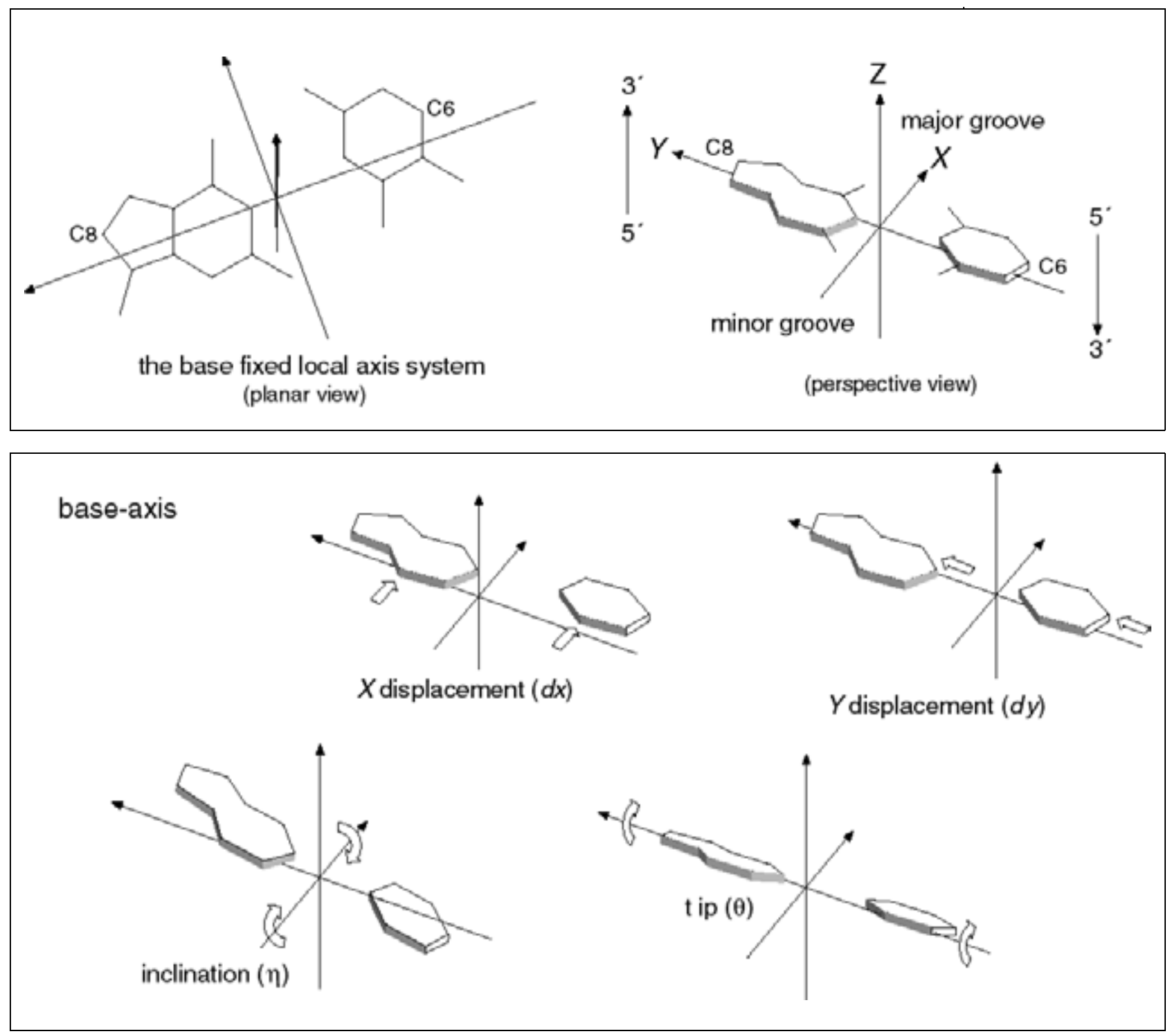

Figure A.1B.3 Definitions of helix parameters for duplex DNA (Dickerson, 1989). The transformations shown are all in the positive direction. 

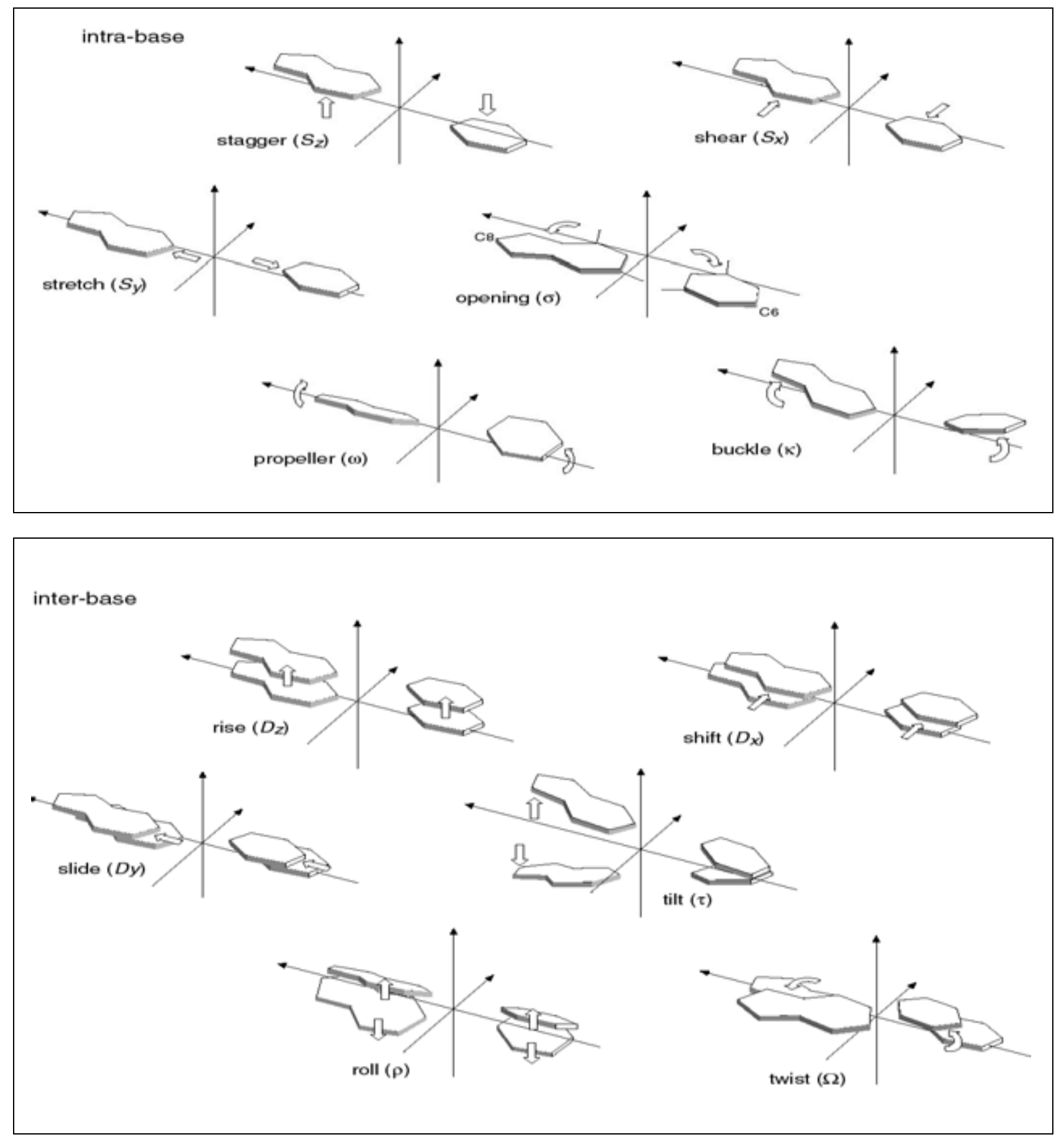

Figure A.1B.3 continued 
<smiles>[R]n1cc(C)c(=O)n([TlH])c1=O</smiles><smiles>[R]n1ccc(NC)nc1=O</smiles>

A:T

Watson-Crick pairings

G:C<smiles></smiles>

reverse wobble pairing<smiles></smiles>

$\mathrm{T} \cdot \mathrm{A}$

Hoogsteen (parallel chains)

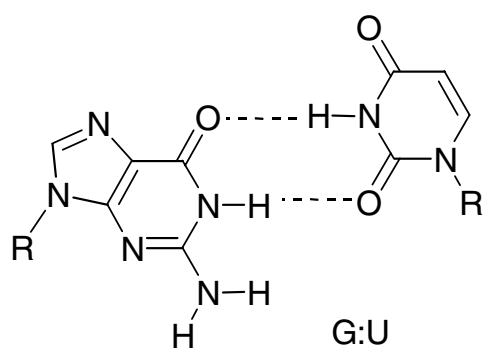

wobble pairing

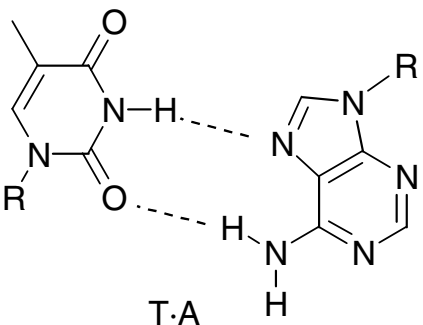

reverse Hoogsteen (antiparallel chains)
Figure A.1B.4 Base pairing schemas. The chemical structures of the nucleotide bases determine the formation of secondary and tertiary structures in nucleic acids. A wide variety of hydrogen bonding schemas (indicated by dashed lines) are possible between different bases. Watson-Crick pairings are perhaps the most widely known and are the basis of the double-helical structure of complementary, anti-parallel DNA strands. Other base pairs can also be accommodated within the double helix, such as "wobble pairings," in which the bases are slightly off-center with respect to each other. By using the N7 hydrogen bond acceptor of the purine bases adenosine and guanosine, an even wider variety of structures becomes possible. Bonds involving N7 of the purine bases allow tertiary structural interactions to occur in nucleic acids, including triple base pairs (Radhakrishnan and Patel, 1994) and "G quartet" (Sen and Gilbert, 1988). A compilation of possible base pairs has been published (Burkard et al., 1999). This information can also be viewed on the World Wide Web at http://www.imb-jena.de/IMAGE_BPDIR.htmI.
Standard

Nomenclature, Data, and Abbreviations 


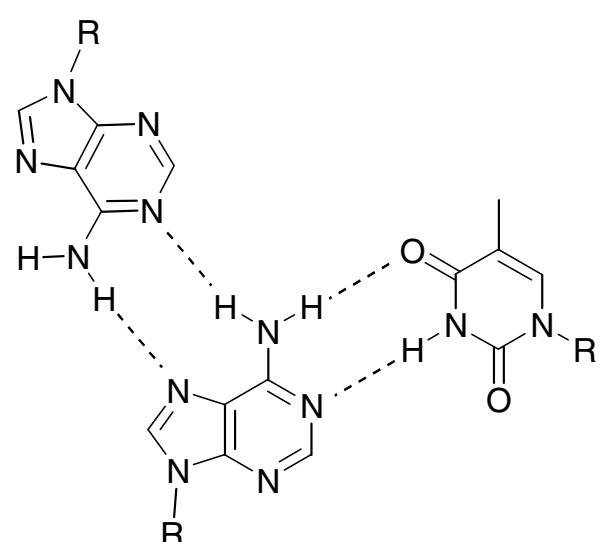

$A \cdot A: T$

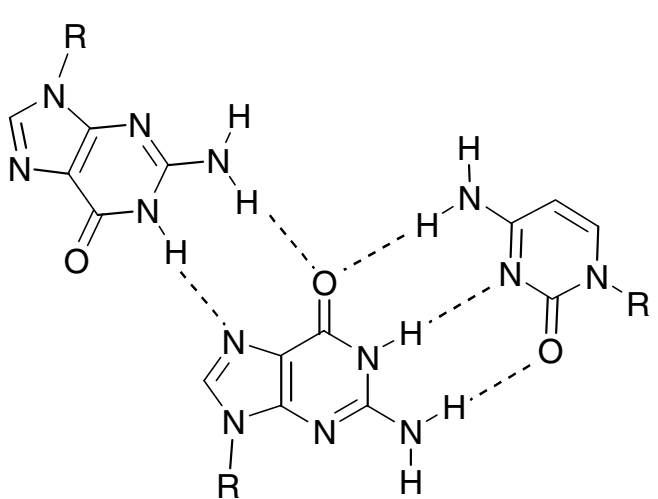

G.G:C

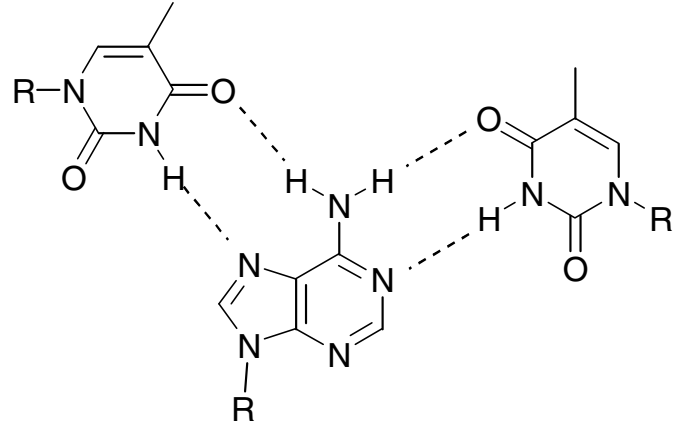

T.A:T

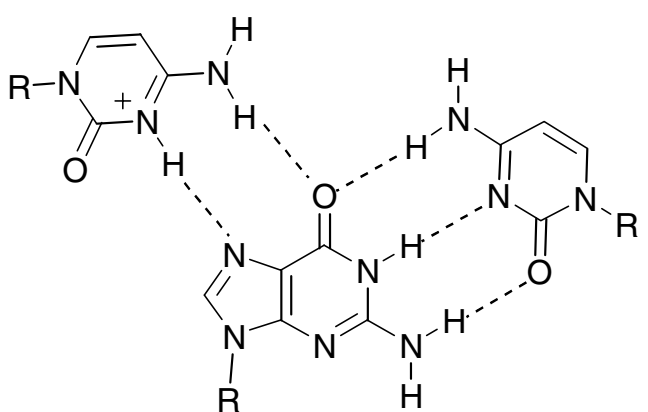

$\mathrm{C}^{+} \cdot \mathrm{G}: \mathrm{C}$

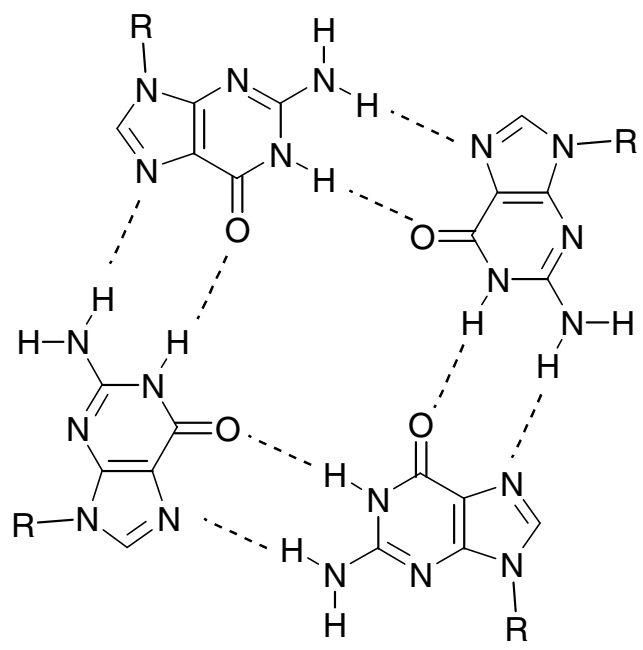

G-quartet

Figure A.1B.4 continued 


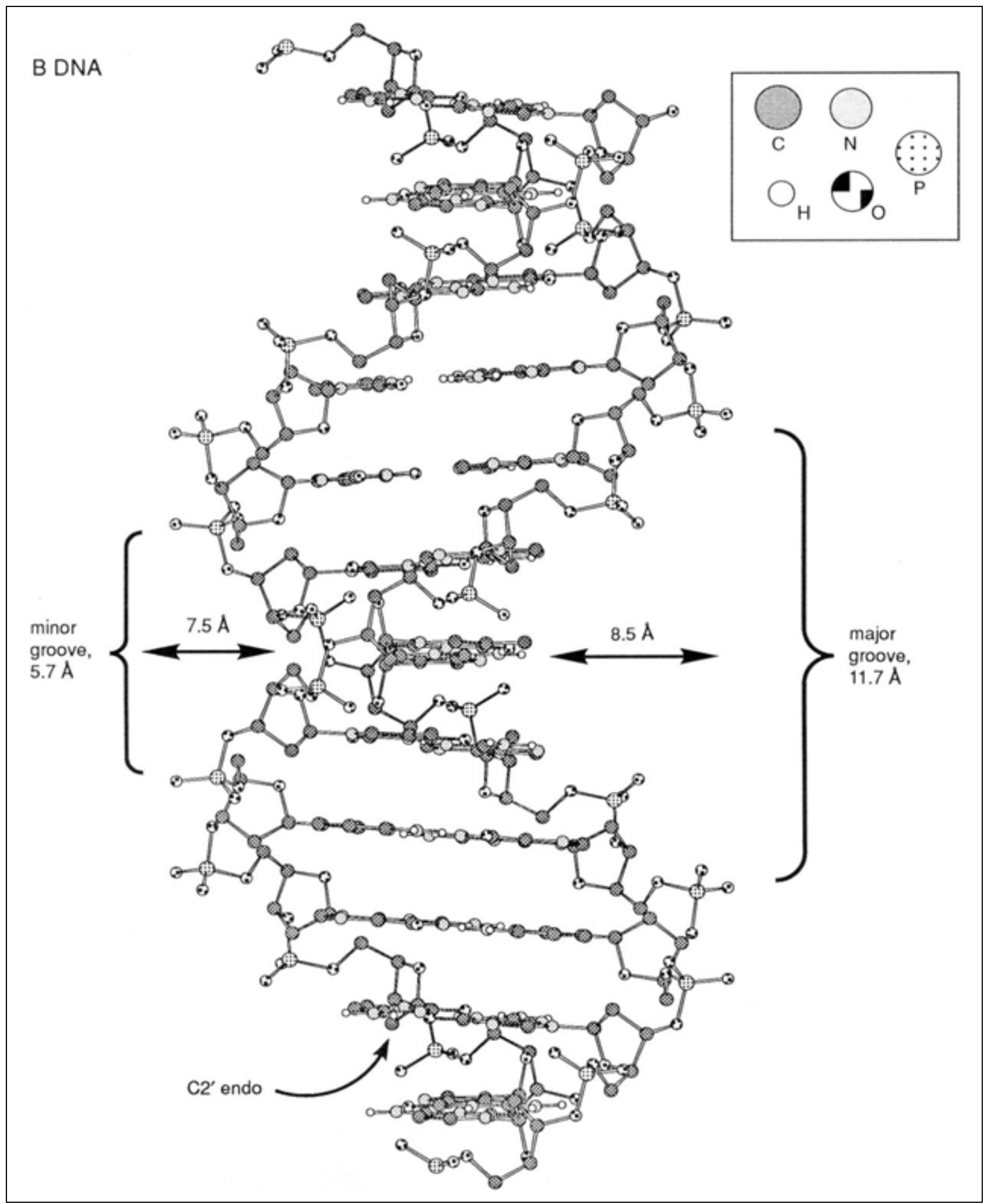

Figure A.1B.5 Nucleic acid secondary structures. The structural consequence of the ability of nucleotides to form Watson-Crick base pairs is nucleic acid double helices. In this figure, the self-complementary 12-mer CGCGAATTCGCG is shown as both A- and B-form helices. Two representations of the $A$ helix have been shown in order to emphasize the depth of the major groove. The arrows and brackets in these figures are not drawn to scale.
While both of these helices are right-handed (in terms of anthropomorphic referents, if you were to point your thumb along a strand in a $5^{\prime}$ to $3^{\prime}$ manner, the twist of the helix would be the same as the curl of your right hand), their structural details are very different: B DNA has roughly 10 bases per full turn, while A DNA and A RNA have 11 to 12; the major groove of $B$-form helices is wide and the minor 
A DNA

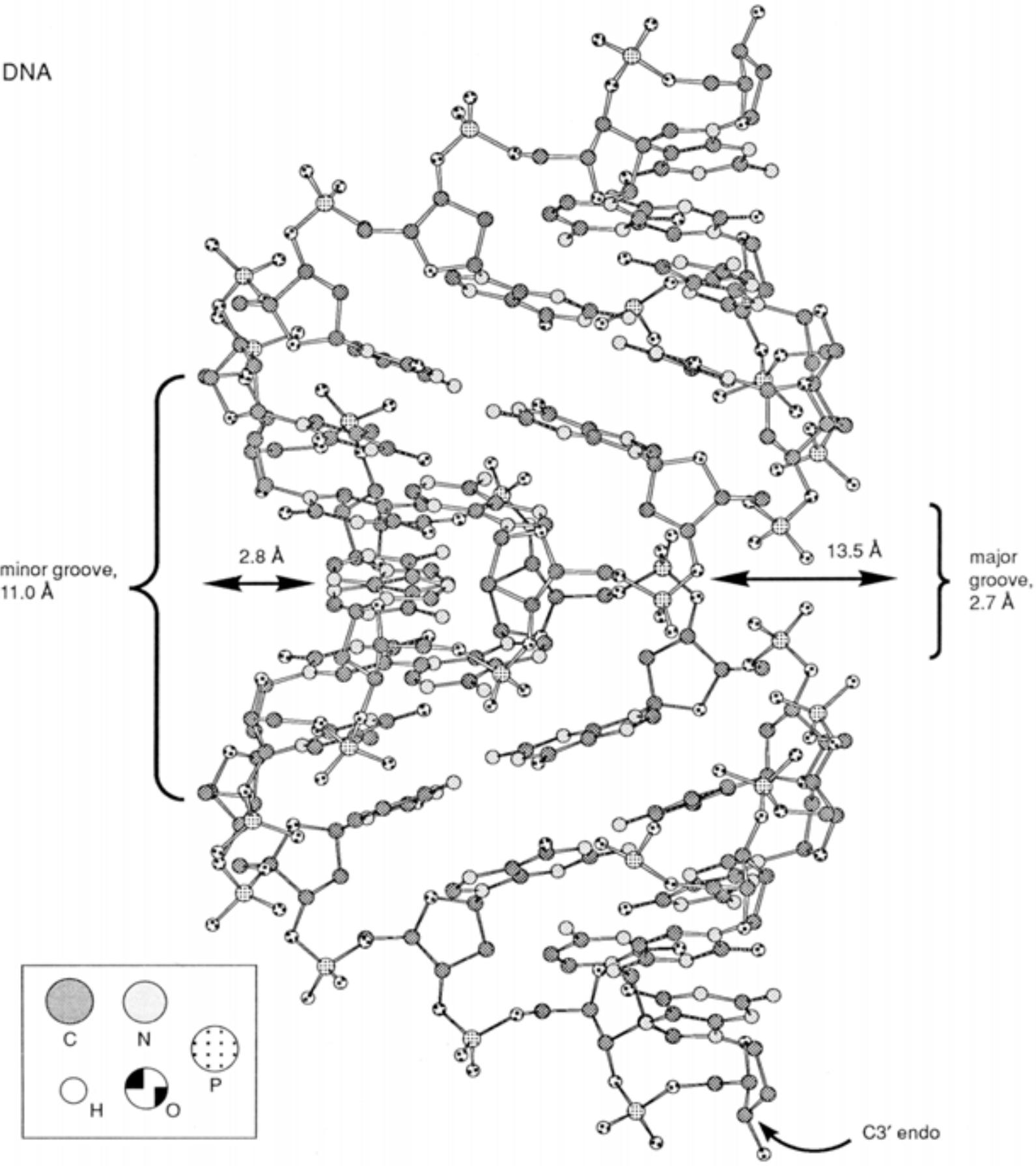

groove is narrow, while for A-form helices this is reversed; in B-forms the base pairs are located close to the helix axis (as can be seen in end-on views), while in A-forms the base pairs are pushed out away from the long helical axis, leaving a "hole" in the middle of the polynucleotide coil (if one imagines DNA as a flat ribbon, then B DNA is twisted from its ends, while A DNA is coiled on itself).

Different helical forms are largely due to differences in sugar stereochemistry. Examples of a 2' endo deoxyribose (found in B DNA) and a $3^{\prime}$ endo deoxyribose (found in A DNA) are indicated.

While there are a variety of other helical forms, the most striking is that found in Z DNA. The Z DNA coil is left- rather than right-handed and contains $G: C$ base pairs where the $\mathrm{G}$ is in the "syn" conformation (shown in the inset).

\section{A.1B.10}




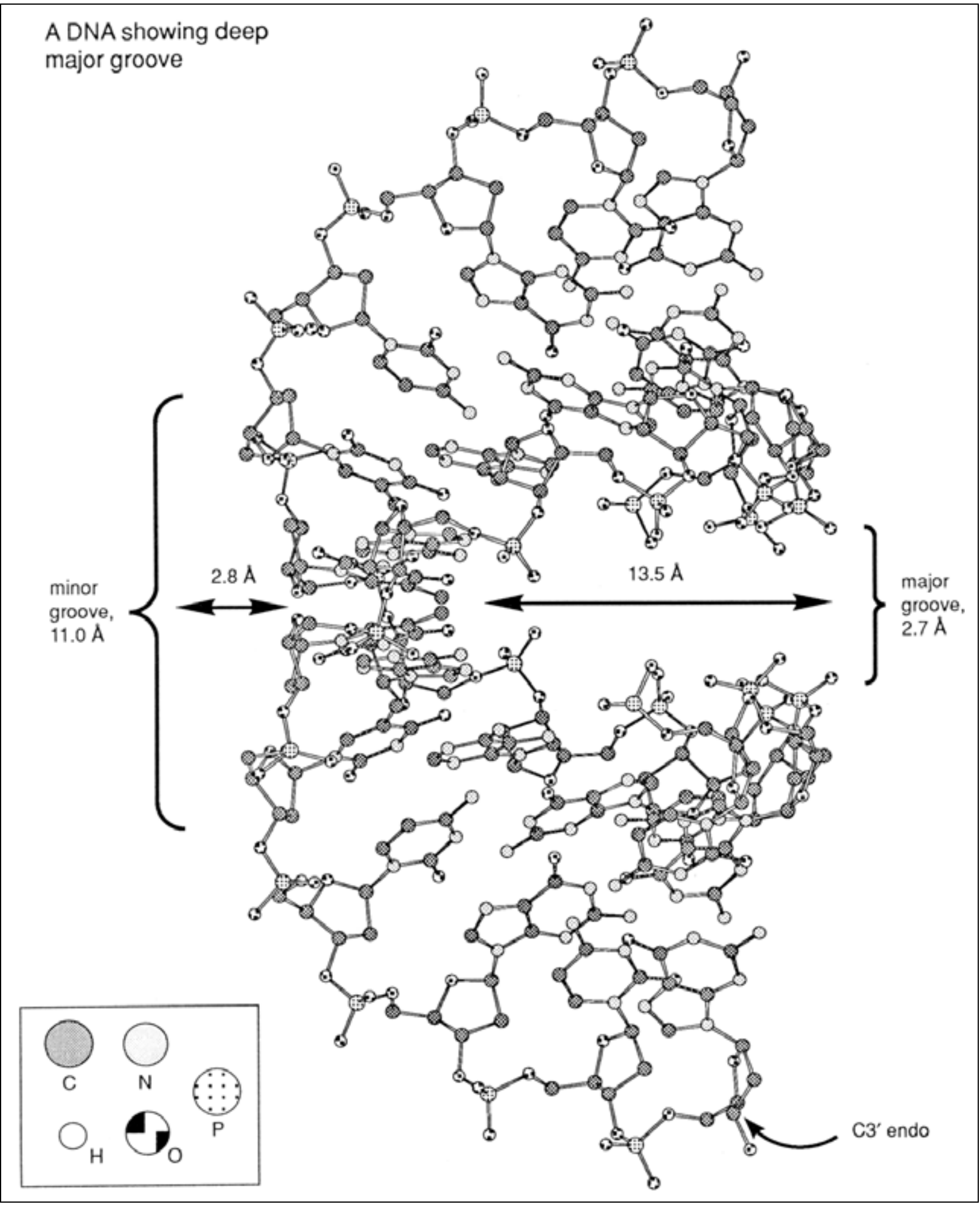

The uneven progression, or zigzag, of Z DNA can be more easily seen when the polynucleotide backbone is shown in isolation; the inset shows the connectivity between phosphates by $5^{\prime}$ to $3^{\prime}$ vector arrows. Because of its odd shape, base pairs actually protrude from what would be a cavity in A or B DNA; thus, Z DNA has a minor but no major groove. This diagram is based on the original structure of alternating C:G/G:C base pairs (Wang et al., 1979). 

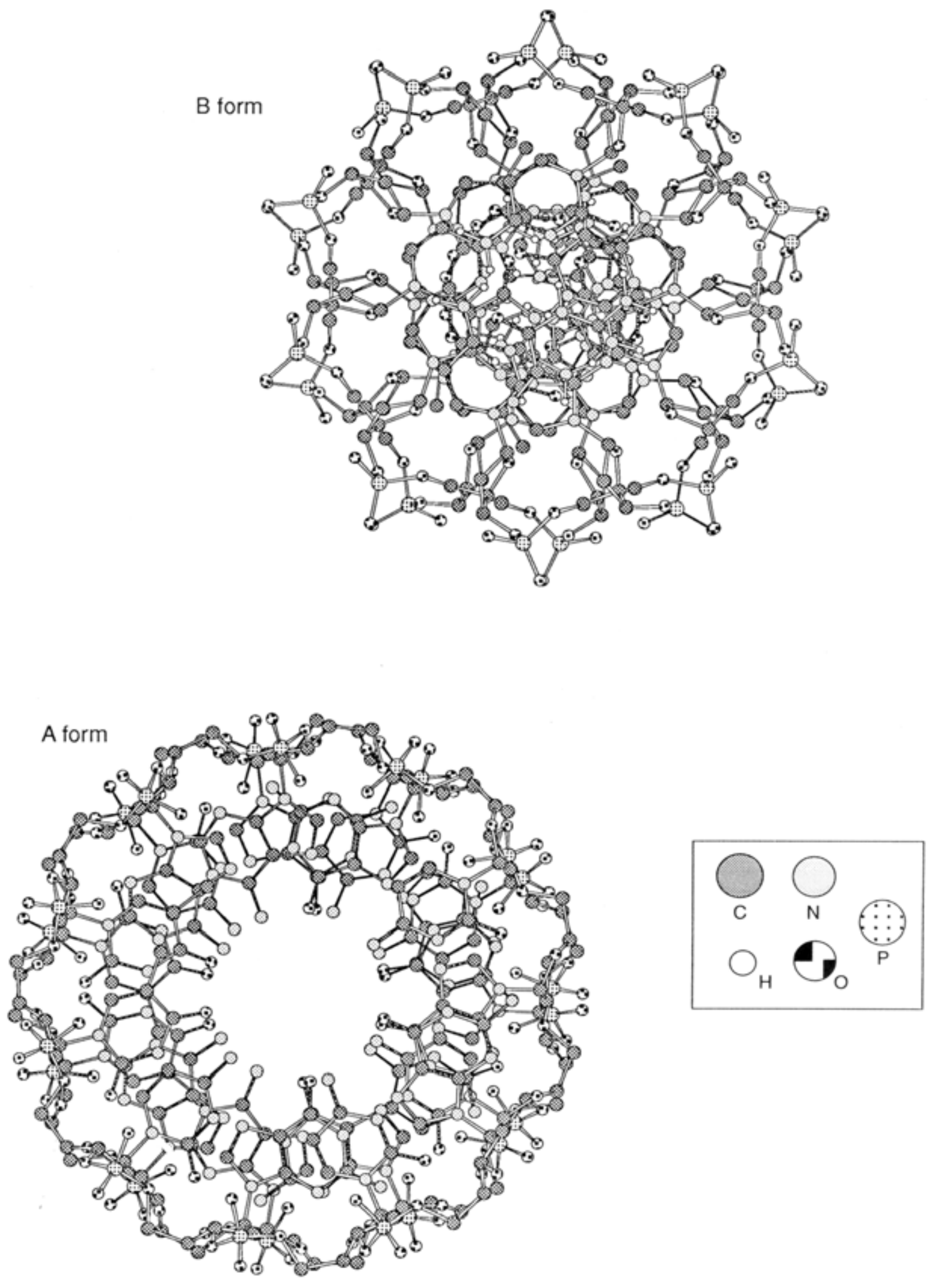

\section{A.1B.12}




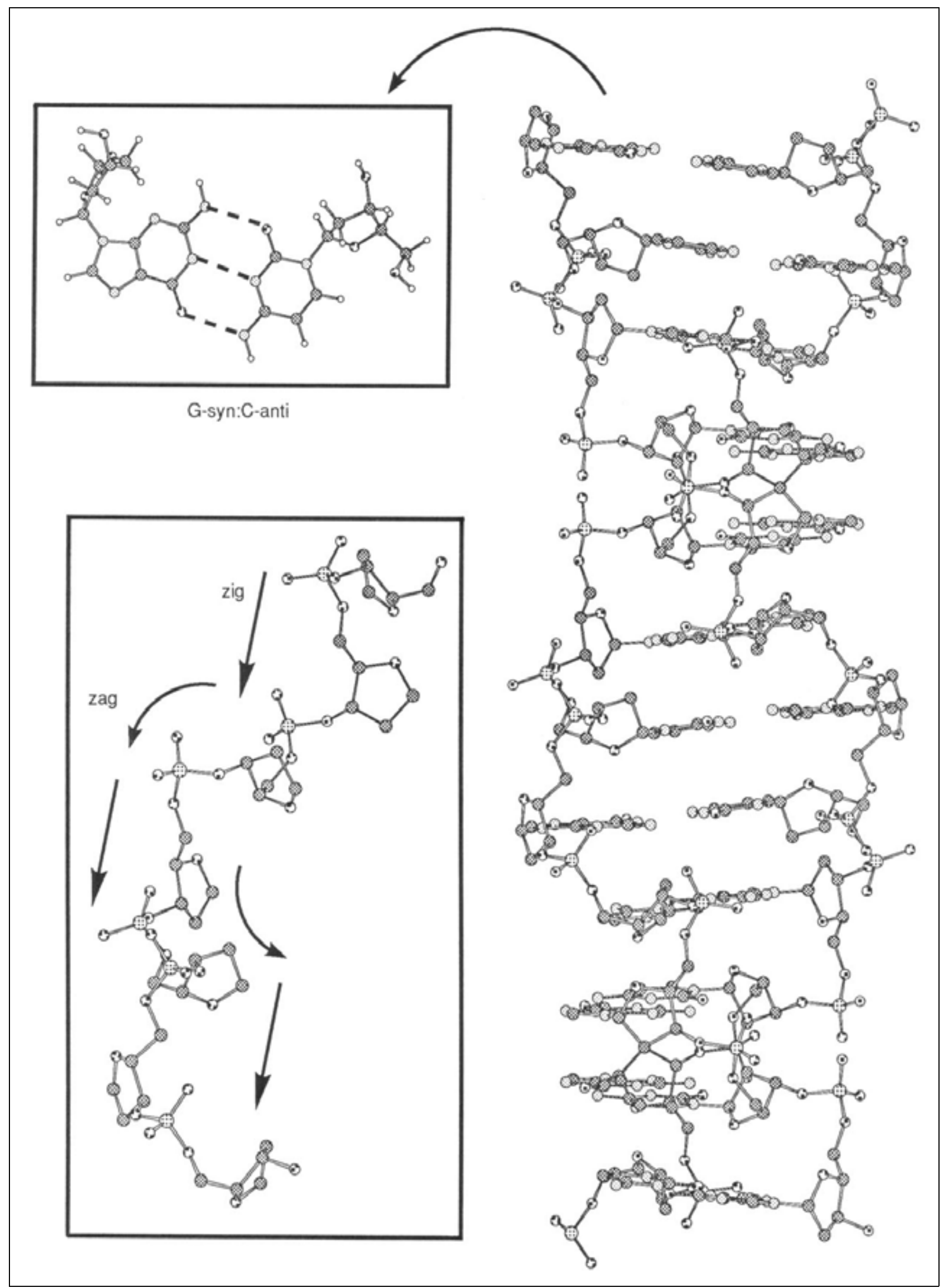




\section{LITERATURE CITED}

Burkard, M.E., Turner, D.H., Tinoco, I. Jr. 1999. Structure of base pairs involving at least two hydrogen bonds. In RNA World, 2nd ed. (R.F. Gesteland, T.R. Cech, and J.F. Atkins, eds.) pp. 675-680, Cold Spring Harbor Laboratory Press, Cold Spring Harbor, N.Y.

Dawson, M.C., Elliott, D.C., Elliott, W.H., and Jones, K.M. (eds.). 1987. Data for Biochemical Research, 3rd ed. Clarendon Press, Oxford.

Dickerson, R.E. 1989. Definitions and nomenclature of nucleic acid structure components. Nucl. Acids Res. 17:1797-1803.

Dickerson, R.E. 1992. DNA structure from A to Z. Methods Enzymol. 211:67-111.

Fasman, G. (ed.). 1975. Handbook of Biochemistry and Molecular Biology, Vol. 1: Nucleic Acids, 3rd ed. CRC Press, Boca Raton, Fla.

Hartman, B. and Lavery, R., 1996. DNA structural forms. Q. Rev. Biophys. 29:309-368.

Heinemann, U., Ailings, C., and Hahn, M., 1994. Crystallographic studies of DNA helix structure. Biophys. Chem. 50:157-176.

Neidle, S. 1999. Oxford Handbook of Nucleic Acid Structure. Oxford University Press, Oxford.

Radhakrishnan, I. and Patel, D.J. 1994. DNA triplexes: solution structures, hydration sites, energetics, interactions, and function. Biochemistry. 33:11405-11416.

Saenger, W. 1984. Principles of Nucleic Acid Structure. Springer-Verlag, New York.

Sen, D. and Gilbert, W. 1988. Formation of parallel four-stranded complexes by guanine-rich motifs in DNA and its implications for meiosis. Nature 334:364-366.

T'so, P.O.P. 1974. Bases, nucleosides, and nucleotides. In Basic Principles in Nucleic Acid Chemistry, Vol. 1 (P.O.P. T'so, ed.) pp. 453-584. Academic Press, San Diego.

Wang, A.H., Quigley, G.J., Kolpak, F.J., Crawford, J.L., van Boom, J.H., van der Marel, G., and Rich, A. 1979. Molecular structure of a left-handed double helical DNA fragment at atomic resolution. Nature 282:680-686.

Adapted by Donald E. Bergstrom, Purdue University, from Current Protocols in Molecular Biology 